\title{
The role of embryology in teratological research, with particular reference to the development of the neural tube and heart
}

\author{
M. H. Kaufman \\ Department of Anatomy, University of Cambridge, Cambridge CB2 3DY, U.K.
}

\section{Introduction}

There are many intriguing questions that the experimental embryologist can attempt to answer which could provide insight into the pathogenesis of many of the commoner types of congenital abnormalities that affect the human population. I should like to draw attention to certain areas of embryological interest, and make some general and personal observations on teratological research. I shall concentrate on two particular areas of interest, namely studies into the pathogenesis of neural tube closure defects and cardiovascular anomalies because these are the topics of my special interests.

Two quite different, but complementary approaches may be employed in experimental teratological research to investigate how certain agents act on specific organs or tissues of the embryo or fetus to induce their abnormal development. The first approach takes cognizance of the nature and chemical structure of the agent under investigation, in order to determine at the biochemical level what the underlying mechanism and principal sites of action are likely to be. The primary effect of the agent may be to disrupt maternal metabolism, and the effect on the embryo or fetus may be secondary to the effect on the mother. In these latter circumstances it is not uncommon for an embryotoxic effect to be produced before any toxic manifestation becomes apparent in the mother.

The second approach takes cognizance of the morphological abnormalities which may be induced by embryonic exposure to a teratogenic agent, in order to determine in the first instance at which stage of gestation the teratogenic insult is likely to have occurred, and, also, its site of action at the cellular and tissue level. In preliminary studies, development may be allowed to proceed for a matter of days, or even to term, before the fetuses are examined, although obviously, depending on the severity of the teratogenic insult, a high proportion of the fetuses may not survive long enough to be examined. By looking at progressively earlier stages, and effectively observing in reverse the pathogenesis of the defect under examination, it may be possible to recognize the direct toxic effects of the agent under investigation, and possibly to determine the extent of any compensatory growth that might have occurred.

It is also instructive to examine the pathogenesis of relatively similar abnormalities involving, for example, the cardiovascular and/or central nervous system, induced by a wide variety of teratogenic agents. The induction of these abnormalities can be compared with the development of similar lesions observed in the offspring of animals bearing specific mutant genes or numerical chromosomal anomalies.

While the concepts of critical or sensitive periods (e.g. see Rychter, 1962) have the advantage of simplicity, they are often inapplicable in the clinical context, as in most instances no history of a single exposure to a teratogenic insult is available. While these acute exposure episodes presumably do occur in man, they often pass unrecognized. Most environmental teratogenic factors probably act over a considerable period of time, and are therefore 'chronic' in 
nature; e.g. when the embryo or fetus is exposed to the metabolic consequences of the maternal ingestion of alcohol, smoking of cigarettes, and numerous other environmental teratogens. It is similarly naive to assume that individual malformations are invariably associated with a single teratogenic insult occurring at a specific period of organogenesis. For example, a cleft palate may be induced in the rat by a single exposure to an appropriate dose of $\mathrm{X}$-irradiation from about Days 10-14 of gestation, indicating that closure of the palate is an extremely complex process with many steps, the overall process extending over a period of days rather than hours (Trasler \& Clarke Fraser, 1977). Each of the numerous steps in the closure process presumably has its own critical period (Clarke Fraser, 1977).

It seems likely that all developmental processes follow this general pattern, and it is only the overall duration of the critical period which varies from organ to organ and tissue to tissue. In addition, embryos in different locations within the uterus may well be exposed to different amounts of the teratogen depending on variations in maternal blood supply, etc. Since this is the case, it is not altogether surprising that even litter-mates may manifest apparently unrelated abnormalities.

Only gross morphological anomalies are likely to be observed at superficial examination if this is carried out 1-2 days after exposure to the teratogenic insult. However, a more detailed histological, or preferably combined histological and ultrastructural, examination often reveals cellular deviations from the norm that may only be manifest clinically much later in gestation, or possibly only well after birth. More subtle changes that may result from, for example, minor alterations in cellular metabolism within the central nervous system will almost certainly not be revealed during such an early examination. Such biochemical deviations may cause changes in the behaviour pattern of the individual which may only manifest themselves when the individual is subjected to an abnormally stressful situation, either physical or mental. An aberrant behaviour pattern may only be detected if special psychological testing is carried out, thus transferring the effect induced during early gestation into the sphere of the behavioural teratologist.

It is especially hazardous to draw conclusions solely from the examination of post-natal material regarding the specific time of exposure to a teratogenic insult if this occurs during the early embryonic period, as it would be almost impossible to distinguish between (a) the abnormal growth induced by the direct effect of the teratogen, (b) secondary destructive processes involving previously normally formed structures, and (c) the effect of tissue regeneration and compensatory growth.

One possible consequence of a teratogenic insult might be death of the embryo shortly after exposure. If the embryo survives, however, there may be abnormality of a specific organ or system which may or may not be associated with general growth retardation or functional derangement of tissue activity. If such abnormalities are induced they may be manifest only after birth. The long-term survival of the individual would largely be determined by the systemic consequences of the resultant abnormality. If, for example, a severe abnormality of the cardiovascular system has been induced, survival to term may occur, but exercise tolerance will almost certainly be severely affected, and premature death may result.

Because I am more familiar with the morphological and descriptive embryological approach, only this aspect of teratological research will be considered here. Examples will be presented which demonstrate how this approach has been utilized to investigate the pathogenesis of certain abnormalities of the central nervous and cardiovascular systems resulting from exposure of experimental animals to teratogenic agents, or as a direct consequence of the presence of an abnormal genome. No attempt has been made to review the very extensive teratological literature in these areas, although particularly relevant work is cited. The following is therefore more in the nature of an account of a general approach which may be used to examine a range of teratological problems in which a detailed knowledge of normal developmental processes is an essential prerequisite. 


\section{Neural tube defects}

Major defects involving the derivatives of the embryonic neural tube, such as anencephaly, hydrocephalus and spina bifida, remain one of the greatest causes of human perinatal mortality and morbidity (Carter, 1976). These conditions are especially prevalent in certain regions of the British Isles (Carter, 1974), where the incidence may be as high as 7 affected infants per 1000 live births, compared to a worldwide incidence of about 1 per 1000 (for reviews, see Willis, 1962; Warkany, 1971; Hughes, 1976; Leck, 1977; Miller \& Lowry, 1977).

Despite the considerable clinical interest in defects of this type, the underlying factors which give rise to them often remain a mystery. The most commonly encountered abnormalities involving the 'spinal' and 'cephalic' regions of the neural tube are spina bifida, which may present minimal to very major clinical problems depending on the degree of severity and extent of the defect, and anencephaly, respectively, the latter being invariably fatal within a matter of hours after birth (Leck, 1977). A considerable number of other conditions which also result from failure of normal development of the neural tube are also occasionally seen (Willis, 1962). Of the various types of neural tube defects encountered it is usual to group conditions such as encephalocele, meningocele and myelocele with spina bifida cystica, and iniencephaly with anencephaly. The equivalent of anencephaly in experimental animals is usually exencephaly, a condition only rarely encountered at full term in man, although this is the commonest anomaly involving the cephalic part of the neural tube during the first trimester of pregnancy, suggesting that in man, at least, exencephaly almost always leads to anencephaly by the second half of gestation (Warkany, 1971).

Various hypotheses have been proposed to account for the high incidence of these defects in certain areas and low incidence in other parts of the U.K. (Carter, 1974, 1976; Leck, 1972, 1974). However, because of the nature of the material and the clinical and ethical problems involved, it has not so far been possible to carry out an acceptable prospective investigation into the factors which may give rise to these defects in man (for observations on surveillance systems, see Weatherall \& Haskey, 1976; Miller \& Lowry, 1977). However, the recent clinical trials to study the possible effect of a high dietary intake of certain vitamins in women who have previously given birth to children with neural tube defects (Smithells et al., 1980) might justifiably be considered to fall into this category.

The association between chromosome disorders and birth defects is well recognized (for reviews, see Hamerton, 1971; Hsu \& Hirschhorn, 1977; and for observations on prenatal diagnosis of these disorders, see Laurence \& Gregory, 1976). The incidence of chromosome anomalies at birth is in the order of 1.5 per 1000 births, and Down's syndrome is the most common cause of severe mental retardation in the U.K. However, the incidence at conception is probably considerably higher (see Boué \& Boué, 1973; and observations by Ford, 1975).

Because of obvious difficulties encountered in obtaining suitable human embryonic and fetal material, any comprehensive attempt to study the pathogenesis of neural tube defects necessitates the use of an experimental animal model in which it is possible to produce an approximate phenocopy of the human defect to be studied. By investigating the underlying mechanisms whereby certain environmental teratogens induce the formation of these phenocopies, it may be possible to gain some understanding of the factors which influence the normal process of neurulation in the human embryo, and to determine at which stages during development the embryo is most sensitive to teratogenic agents.

The mouse is one of the most useful experimental animals in this area of research as, in addition to being sensitive to many teratogens that induce neural tube defects, numerous mutant strains exist which also develop abnormalities involving the 'spinal' and 'cephalic' parts of the neural tube, the skull, and vertebral column (Kalter, 1968; Staats, 1975, 1976).

Despite the vast literature that has accumulated on the cellular events thought to be important in the process of neurulation (for recent review, see Karfunkel, 1974), particularly in 
non-mammalian species, only a superficial overall picture of the sequential changes which take place during neurulation in the cephalic region of any mammalian embryo exists at present. Similarly, minimal information is available on the interrelationship between this complex process and the formation of the optic primordia (see, however, Streeter, 1942; O'Rahilly, 1966). Consequently, it is essential to establish this baseline information (Pl. 1, Figs 1-6) before progressing towards the next goal of determining, initially at the gross morphological level and later at the ultrastructural level, the events that lead to the development of abnormalities of the cephalic region of the neural tube. Closure of this part of the neural tube is completed in embryos which possess about 20 pairs of somites (Kaufman, 1979), and is an essential prerequisite before facial development can take place, involving as it does the very complex movements of the various facial 'processes' (for standard text-book description, see Hamilton \& Mossman, 1972).

\section{Neural tube defects in the mouse}

One of the main problems associated with experimental studies on neural tube anomalies, and this equally applies to experimentally induced abnormalities of other organ systems, is that the mode of action of individual teratogens may differ from the mechanism which usually leads to the formation of an apparently similar defect in the human fetus. In order to go some way towards countering this objection, the influence of two teratogens known to effect neural tube closure was investigated (O'Shea \& Kaufman, 1979a, b, 1980, 1981) and a translocation-bearing strain of mice in which a high proportion of the offspring developed neural tube defects (Snell's translocation; Snell, Bodeman \& Hollander, 1935; O’Shea, 1979) was also studied.

The emphasis of O'Shea \& Kaufman's work has largely been towards understanding the relationship between the gross morphological damage induced, and the changes observed within and between individual neuroepithelial cells. These investigations complement the recent work by Solursh \& Morriss (1977; see also, Morriss \& Solursh, 1978) who have stressed the part played by the underlying mesenchyme cells and the biochemical components of the intercellular matrix during the process of neurulation (for observations on the role of extracellular components during morphogenesis, see Kochhar \& Larsson, 1977).

Two major experimental approaches have been employed, namely the in-vivo approach in which a particular agent is given to a pregnant female during the early post-implantation period, and the in-vitro approach, often carried out in parallel, in which isolated embryos maintained in culture (New, Coppola \& Terry, 1973) have been exposed to the same agents over approximately the same period of embryonic development. The teratogens tested were acetaldehyde and copper.

Acetaldehyde, the primary metabolite of ethyl alcohol, was tested as part of an investigation into the teratogenic properties of ethanol, to determine its possible role in the fetal alcohol syndrome (Jones, Smith, Ulleland \& Streissguth, 1973), as no previous experimental studies had been carried out to examine the possible effect of acetaldehyde on the developing mammalian embryo (for discussion of possible role of acetaldehyde in ethanol toxicity, see Akabane, 1970; Truitt \& Walsh, 1971; Rahwan, 1974; Mulvihill \& Yeager, 1976). Many workers have investigated the influence of ethanol on embryonic and fetal development when given by different routes to experimental animals (Papara-Nicholson \& Telford, 1957; Sandor \& Amels, 1971; Tze \& Lee, 1975; Kronick, 1976; Rosman \& Malone, 1976; Chernoff, 1977; Randall, Taylor \& Walker, 1977; Henderson \& Schenker, 1977). There was developmental and/or growth retardation, an increased incidence of resorptions and perinatal mortality, and a range of congenital abnormalities involving particularly the central nervous system. The resultant abnormalities were observed when litters were examined at term and during the early post-natal period. However, in only one of the ethanol studies were mid-gestation embryos examined (Sandor \& Amels, 1971). 
To study the effect of acetaldehyde free from the effect of ethanol, different groups of pregnant mice were injected during the early post-implantation period with 1 or $2 \%$ acetaldehyde in saline $(9 \mathrm{~g} \mathrm{NaCl} / 1)$ on Days 7,8 and 9 of gestation, and the uterine contents were examined on Days 10 or 12 (Day 1 = the day on which a vaginal plug was observed).

The experimental embryos examined on Day 10 had a high incidence of developmental delay (Pl. 2, Figs 7 and 8) and anomalies of closure of the cranial and caudal extremities of the neural tube (P1. 2, Fig. 11) (for experimental details, see O'Shea \& Kaufman, 1979a). More detailed examination showed that major damage had been sustained by the neuroepithelium: the cells appeared to have rounded-up (P1. 2. Figs 8, 9 and 10). This impression was confirmed by transmission electron microscopy: the microtubules and microfilaments appeared to be partially or completely disrupted (O'Shea, 1979; O'Shea \& Kaufman, 1981). Damage to these cytoskeletal elements would almost certainly account for the failure of closure of the neural tube in the 'cephalic' and 'spinal' regions, and the abnormal appearance of the neuroepithelium in the obviously damaged areas and in the apparently normally closed regions of the neural tube.

Similar studies of the teratogenic effect of copper were carried out (O'Shea \& Kaufman, $1979 \mathrm{~b}, 1980$ ) as part of an investigation into the possible consequences in man of conception in the presence of copper-bearing intrauterine contraceptive devices (IUCDs). Copper has been shown to be blastocyst-lethal at concentrations above $2.5 \times 10^{-5} \mathrm{M}$ in the mouse (Brinster \& Cross, 1972; Naeslund, 1972), lethal to 15- and 30-somite rat embryos at concentrations higher than $5 \times 10^{-4} \mathrm{M}$, although lower levels had no observable effect on development (Webb \& Coppola, 1976), and teratogenic when administered to pregnant hamsters on Day 8 of gestation (Ferm \& Hanlon, 1974). Various types of abnormalities were reported in surviving hamster offspring, many of which involved mid-line closure defects both of the neural tube and of the anterior thoracic and abdominal walls. Gosden, Ross, McGovern \& Reid (1979) have described severe developmental retardation in spontaneously aborted fetuses, and cases of intrauterine death in other pregnancies occurring in women with a copper IUCD in situ.

In the first series of experiments, copper in the form of an aqueous solution of copper sulphate was injected intravenously via the tail vein into pregnant female mice on the morning of Day 7, Day 8 or Day 9 of pregnancy (see O'Shea \& Kaufman, 1979b). Autopsies were mostly carried out on Day 10, although an additional few females were injected with copper on Day 8 and the uterine contents examined on Day 12 of gestation.

Depending on the stage of embryonic development at the time of injection, the copper was teratogenic or embryo-lethal. The most sensitive period for the production of abnormalities of the neural tube and heart was fairly circumscribed, occurring somewhere between the mornings of Days 8 and 9 of gestation. The neural tube defects observed mostly involved failure of elevation of the cephalic neural folds, and consequently resulted in closure defects involving a major or minor part of this region. In over a quarter of the embryos with abnormalities of the neural tube, abnormalities of the heart were also present, while in an additional $10-15 \%$ only abnormalities of the heart were observed.

By Day 12, about half of the surviving fetuses had abnormalities involving the head region. In about a quarter of the less severely affected fetuses, the region overlying the 4th ventricle appeared to be collapsed, whereas in the majority of the remainder an open neural tube defect was present extending from the caudal part of the presumptive mid-brain to just rostral to the otocysts (Pl. 2, Figs 12 and 13).

In a parallel series of experiments, pregnant females were autopsied on the morning of Day 9 of gestation, and embryos which possessed an intact yolk sac and ectoplacental cone were explanted into roller bottles (New et al., 1973) containing heat-inactivated immediatelycentrifuged rat serum prepared as described by Steele \& New (1974). Various concentrations of copper sulphate had previously been prepared and added to the serum samples. At the end of the 36-h culture period, the embryos were isolated and the presence or absence of gross abnormalities noted. While the lowest level of copper tested $\left(5 \times 10^{-6} \mathrm{M}\right)$ had 


\section{PLATE 1}

Scanning electron micrographs showing the changes which take place in the overall appearance of the mouse embryo from the late pre-somite period, on Day 8 , to the limb-bud stage, early on Day 12.

Fig. 1. Dorsal view of embryonic region of an advanced egg-cylinder containing a late pre-somite stage embryo. The two headfolds (arrowed) are separated by the neural groove. The torn edges of the amnion (A) and extra-embryonic endoderm (E) are also clearly seen.

Fig. 2. Antero-lateral view of 5-6-somite embryo. The embryonic membranes have been torn open to expose the cephalic and caudal extremities of the embryo. Note the two headfolds $(\mathrm{H})$ and the allantois (A). The embryo is in the characteristic 'unturned' position.

Fig. 3. Dorsal view of embryo at a similar stage of development to that illustrated in Fig. 2. The embryo has been 'flattened out' to demonstrate that the neural folds, possibly in the low cervical or upper thoracic region, have apposed and are in the process of fusion. Note the relatively advanced state of development of the cephalic region, and poorer degree of differentiation in the caudal extremity of the embryo which abuts onto the allantois (A).

Fig. 4. Embryo with approximately 10 somites. A large region of the neural tube has been formed, but the neural folds in the cephalic (A) and caudal (C) extremities of the embryo have yet to fuse. The outlines of the somites (arrowed) are clearly visible just lateral to the dorsal midline. The two 'bulges' in the cephalic region represent the area overlying the optic indentation $(\mathrm{O})$, and the first branchial arch (1).

Fig. 5. Embryo with approximately 25 somites. By this stage, only the caudal region of the neural tube (i.e. the caudal or posterior neuropore, $N$ ) has yet to close. The 'bulge' overlying the optic vesicle (V) is clearly seen, as are the first (1) and second (2) branchial arches. The ridge (R) along the side of the embryo from which the limb buds develop is also apparent.

Fig. 6. Advanced limb-bud stage embryo isolated early on Day 12. Note that the neural tube has closed along its entire length. The 'bulge' overlying the optic vesicle $(O)$ is clearly seen, as is the naso-lacrimal groove (arrowed). The limb buds are spade-like, and the apical ectodermal ridge $(\mathrm{R})$ is clearly seen at the peripheral margin of the hind-limb bud.

\section{PLATE 2}

Scanning electron micrographs illustrating the normal appearance of the neural ectoderm (neuroepithelium) and its appearance after embryonic exposure to acetaldehyde.

Fig. 7. Control headfold-stage early-somite embryo isolated early on Day 9. Note the smooth appearance of the neural ectoderm, and the presence of the neural folds.

Fig. 8. Acetaldehyde-treated embryo isolated on Day 10. Note the considerable degree of growth retardation and the rounded-up appearance of the neuroepithelial cells.

Fig. 9. Close-up view of the neuroepithelium of a control embryo.

Fig. 10. Close-up view of the neuroepithelium of an acetaldehyde-treated embryo. The cells at the surface of the neural ectoderm have rounded-up and lost their normal contacts with their neighbours. This illustration is at the same magnification as the area of neural ectoderm shown in Fig. 9.

Fig. 11. Acetaldehyde-treated embryo at the 12-14-somite and early 'turned' stage. Note the abnormal appearance of the cephalic and caudal extremities of the neural tube. In the cephalic region a small bridge (B) has formed between the presumptive fore- and mid-brain regions. The neural folds overlying the fore-brain $(F)$, the mid-brain $(M)$ and hind-brain $(H)$ regions have failed to fuse, and are markedly everted. The primitive heart tube is also clearly seen (arrowed), as is the first branchial arch (1). This embryo would almost certainly have developed exencephaly.

Figs 12 and 13. Lateral (Fig. 12) and postero-lateral (Fig. 13) views of the cephalic region of an embryo isolated early on Day 12, having previously been exposed in vivo to copper sulphate on Day 8. Note that the embryo has developed exencephaly mainly involving the mid-and hind-brain regions. The boundary zone between the surface and neural ectoderm is clearly seen (Fig. 12, arrowed). Apart from the abnormality in the cephalic region, the rest of this embryo appeared to be quite normal, although similarly treated embryos developed, in addition to exencephaly, cardiac abnormalities. 
PLATE 1
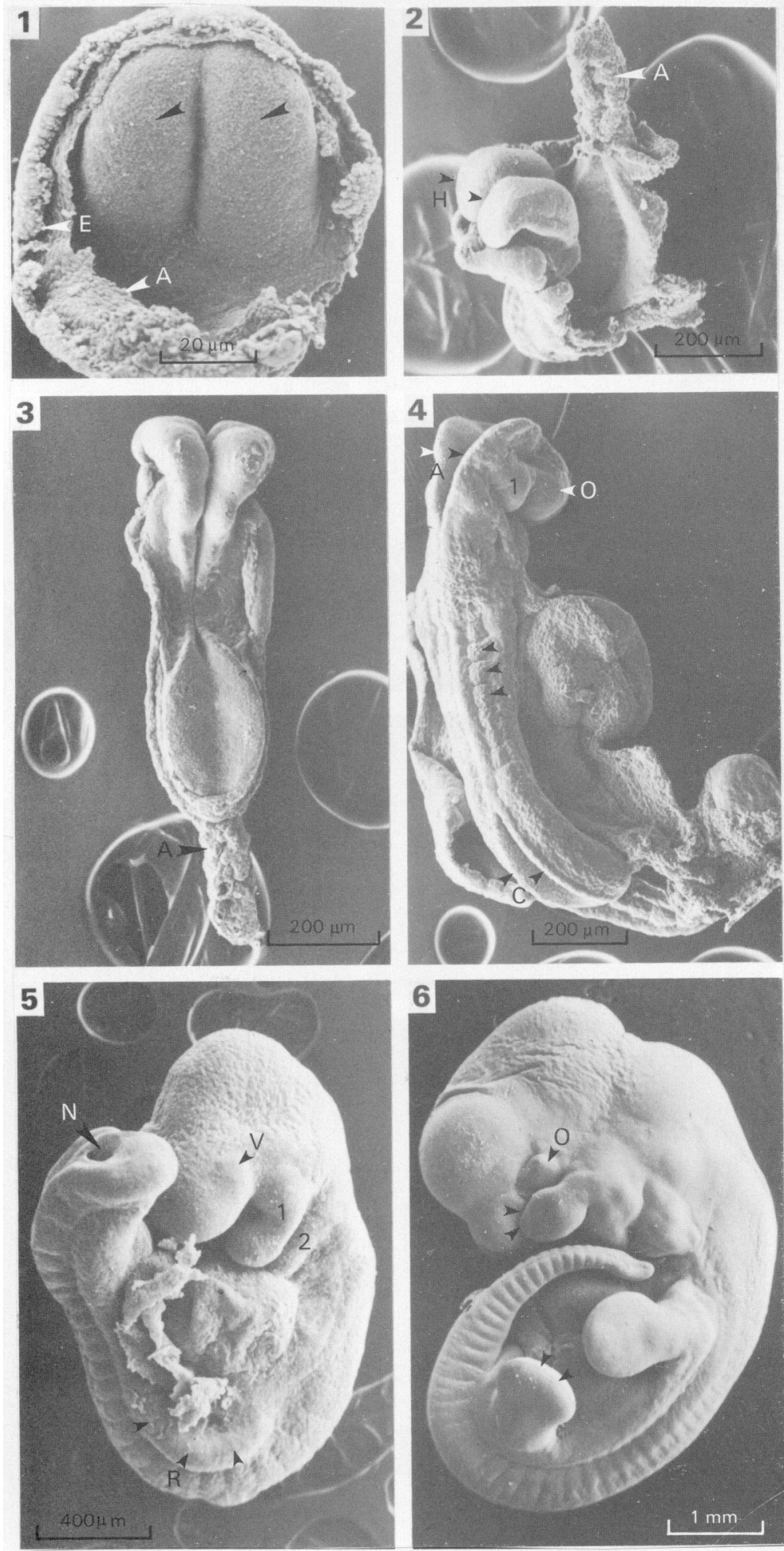
PLATE 2
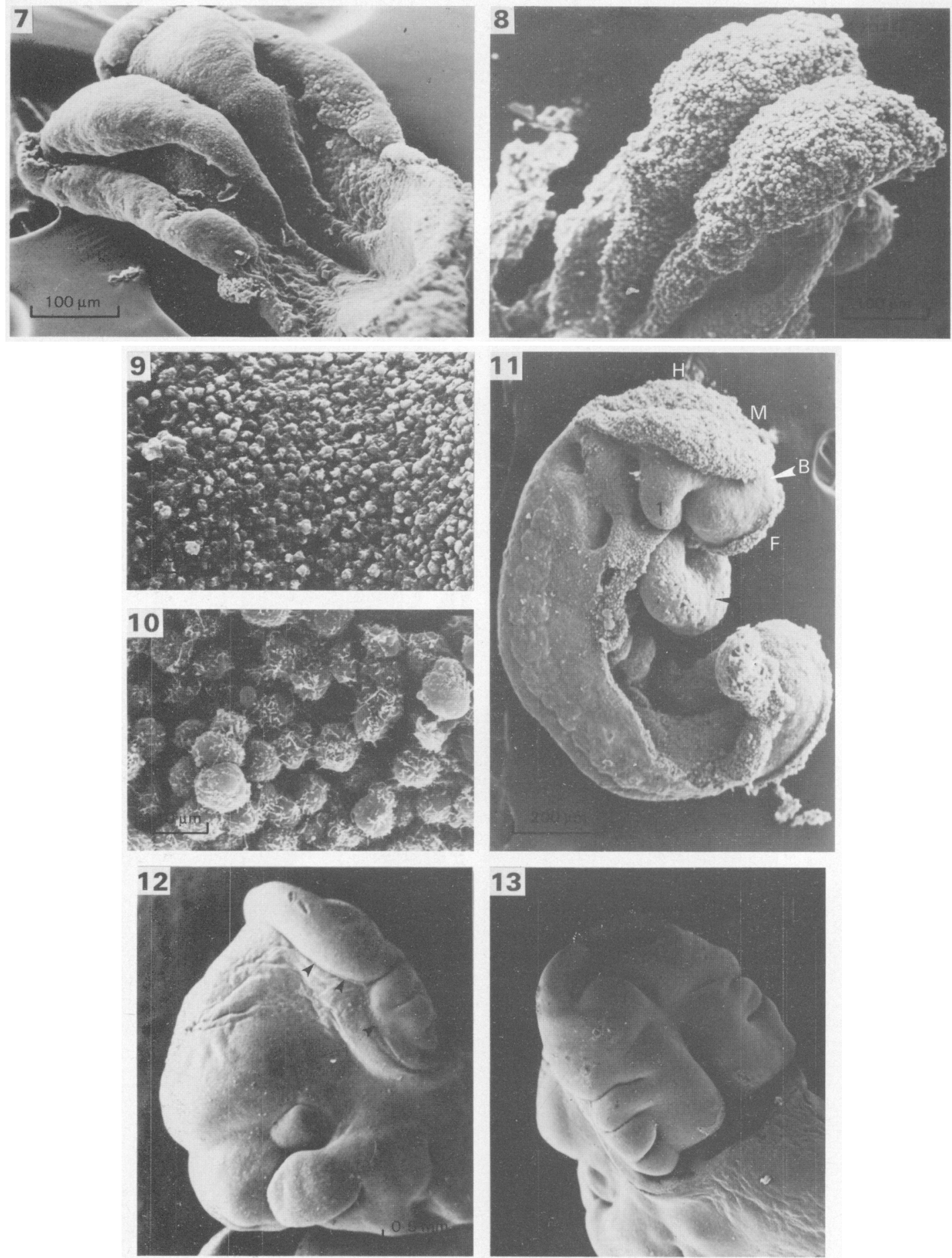
PLATE 3
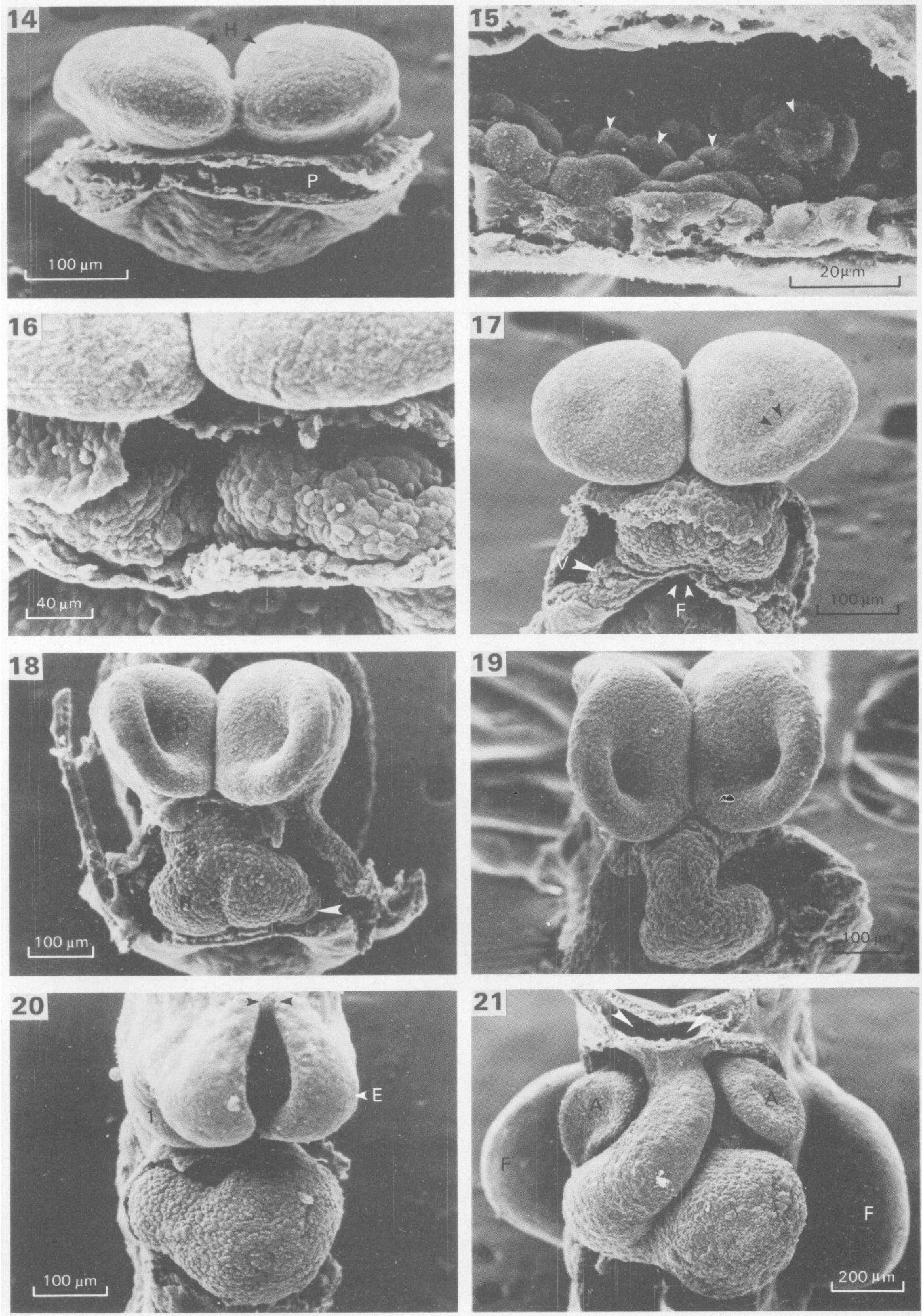
PLATE 4
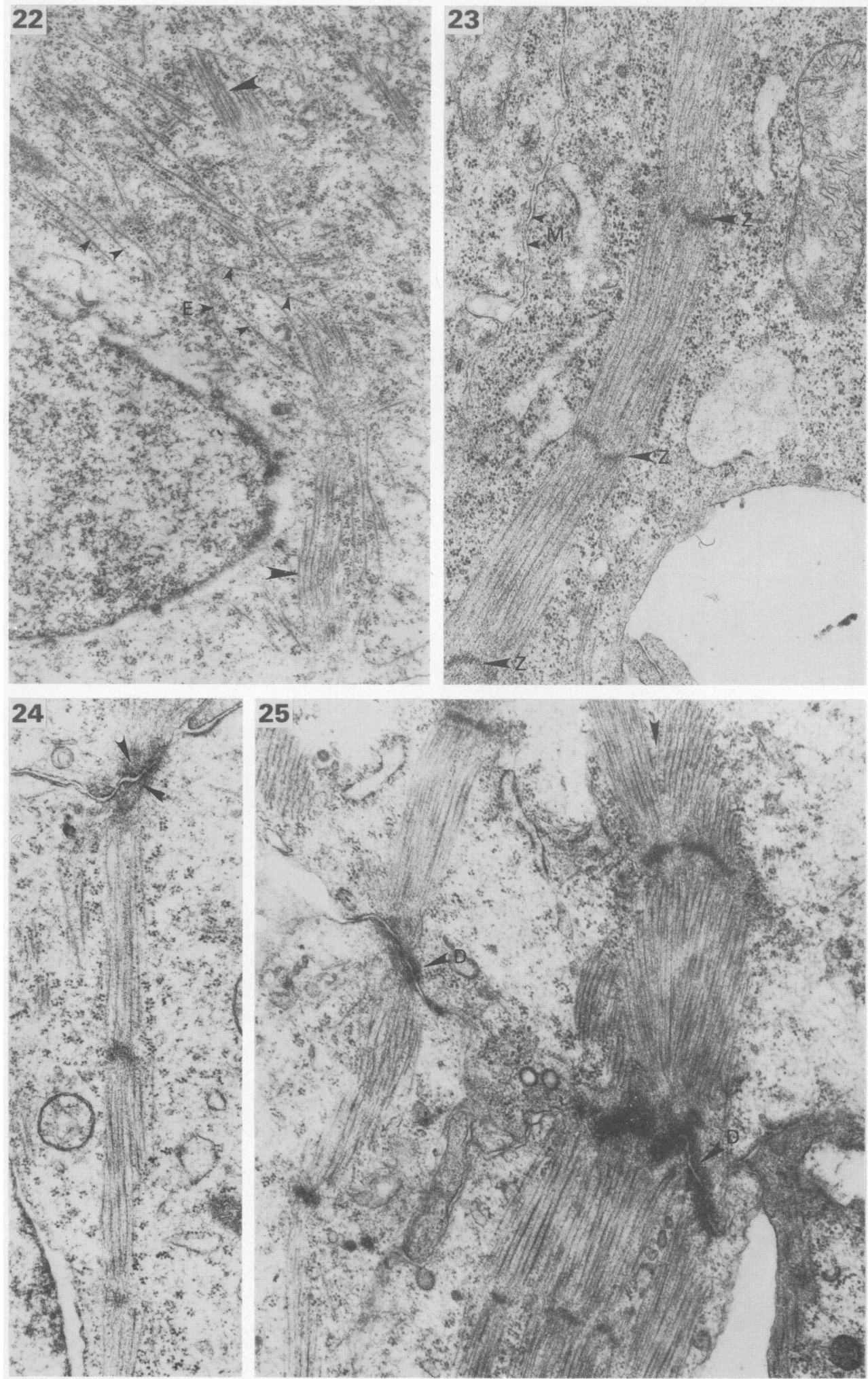
PLATE 3

Scanning electron micrographs showing the development of the embryonic mouse heart from the 'cardiogenic plate' stage, observed early on Day 9, to the formation of the primitive four-chambered heart, observed on Day 11. The pericardial cavity and its contents have been exposed in these embryos by removal of the overlying antero-ventral layer of surface ectoderm and the adherent subjacent mesenchyme and layer of parietal pericardium.

Fig. 14. Frontal view of 1-2-somite embryo. The headfolds $(\mathrm{H})$, foregut pocket $(\mathrm{F})$ and pericardial cavity $(\mathrm{P})$ are clearly seen.

Fig. 15. Close-up view of part of the exposed pericardial cavity of the embryo illustrated in Fig. 14. A small collection of presumptive myocardial cells can be identified (arrowed) protruding from the ventral splanchnic wall into the pericardial cavity.

Fig. 16. Frontal view of 3-4-somite embryo. The two cardiac rudiments abut against each other in the midline, and are separated by a deep furrow. They are functionally separate entities each containing a medially-directed blind-ending lumen which is lined by a single layer of endothelial cells.

Fig. 17. Frontal view of 5-6-somite embryo. The two horns of the sinus venosus (V) pass around the foregut pocket $(F)$ to enter at the venous end of the median primitive heart. A very early stage in the formation of the optic pit (arrowed) may be seen.

Fig. 18. Frontal view of 6-7-somite embryo. The enlargement of the ventricular region of the primitive heart causes characteristic 'bulges' to appear on either side of the midline which are separated by a shallow groove. The primitive left atrial dilatation is just visible (arrowed). The right ventricular dilatation $(R)$ is continuous with the bulbus cordis $(B)$. Note also the increase in the depth of the optic pits $(\mathrm{O})$ compared to the situation illustrated in Fig. 17.

Fig. 19. Frontal view of an 8-9-somite embryo, the heart is now clearly S-shaped, with a pronounced ventral curvature. The bulbar region (B) is continuous cranially with the myocardial 'mantle' tissue which embraces the origins of the first aortic arch arteries.

Fig. 20. Frontal view of a 10-12-somite embryo. Note in particular the marked degree of ventricular dilatation and the relative decrease in diameter of the bulbus cordis compared to the situation illustrated in Fig. 19. Ventral fusion of the cephalic neural folds occurs initially at two sites: in close proximity to the buccopharynx, and at the junction between the presumptive foreand mid-brain (arrows). Note also the obvious optic eminences (E) overlying the deep optic pits, and the location of the first branchial arch (1).

Fig. 21. Frontal view of an advanced-somite embryo isolated on the morning on Day 11. The head has been removed to facilitate observation of the upper ventral surface of the heart. The right and left auricular appendages (A) of the atria are clearly seen on either side of the cranial (distal) part of the bulbus cordis. The proximal part of the bulbar region becomes absorbed into the right ventricle. The origins of the first aortic arch arteries are just visible (arrowed). Note the pronounced bulbo-ventricular sulcus and the location of the fore-limb buds $(F)$.

\section{PLATE 4}

Transmission electron micrographs illustrating the 2 principal features associated with the transition of cardiac cells from the 'undifferentiated' myoblast stage to the 'differentiated' myocyte: the laying down of contractile elements within the cytoplasm to form sarcomeres, and the development of intercalated disks. Figures 22-24 are sections taken from the heart region of a 6-somite mouse embryo. The area illustrated in Fig. 25 is taken from the ventricular region of a 14-16-somite mouse embryo.

Fig. 22. Area of cytoplasm proximal to the nucleus of a myocardial cell in which randomly orientated filamentous elements (E) may be observed. Several areas where a degree of organization is apparent are also seen in this field (large arrows). $\times 14400$.

Fig. 23. Area of cytoplasm towards the periphery of a cell in which a considerable degree of myofibrillogenesis has taken place with the formation of a group of sarcomeres separated by regularly spaced $\mathrm{Z}$-bands $(\mathrm{Z}$, arrowed). The bundle is relatively narrow, and quite close to the cell membrane $(M) . \times 700$.

Fig. 24. Bundle of filamentous elements organized into sarcomeres which are in continuity with similar elements in another cardiac cell via a primitive intercalated disk (arrowed). $\times 700$.

Fig. 25. Considerably more organized state of myofibrillogenesis than that illustrated in Figs 22-24. Most of the contractile elements appear to be organized into sarcomeres, separated by well-developed Z-bands. A suggestion of $A$ and $I$ banding may also be observed in the sarcomeres proximal to the intercalated disk (D). A degree of branching of this bundle is also apparent (arrowed) $\times 700$. 
no obvious embryotoxic effect, a proportion of the embryos tested with $2.5 \times 10^{-5} \mathrm{M}$ copper developed neural tube defects involving the cephalic region. However, with the highest concentration of copper tested $\left(5 \times 10^{-5} \mathrm{M}\right)$ severe malformations involving the neural tube in the head region were frequently observed. The most common defect appeared to result from failure of elevation of the cephalic neural folds, and consequently resulted in failure of closure of the neural tube in the affected region. Despite the grossly abnormal appearance of the head region, almost all of the treated embryos had a beating heart and functioning yolk-sac circulation at the end of the culture period. The defects observed in these in-vitro experiments were therefore remarkably similar to those observed in the in-vivo experiments, suggesting that in-vivo administration of copper has a direct teratogenic effect on the embryo. The similarity of effects of copper on mouse embryos in vivo and in vitro suggests that the pathological changes observed probably resulted from a direct embryotoxic effect of the copper.

A considerable number of the acetaldehyde- and copper-treated embryos showed gross abnormalities involving closure defects of the 'cephalic' and 'spinal' regions of the neural tube. Acetaldehyde-exposed embryos with 25-30 pairs of somites, which appeared externally to be morphologically quite normal, often showed evidence of neuroepithelial damage involving all regions of the brain and neural tube. Similar changes were also induced by embryonic exposure to copper, although, in addition to defects involving the neural tube, a higher proportion than in the acetaldehyde series developed cardiac abnormalities. Ultrastructural examination of the neuroepithelial cells (O'Shea \& Kaufman, 1980) revealed, in addition to closure defects at different levels along the neural axis, a considerable degree of damage to the intracellular cytoskeletal elements. Aggregations of filamentous material were also observed within the cytoplasm of neuroepithelial cells which were otherwise devoid of microtubular elements. It was therefore concluded that damage to these cytoskeletal structures may have played a considerable part in the neural tube damage induced by copper, because these elements are thought to play an important role in neuroepithelial cell elongation, which is an essential step during the process of neurulation (Karfunkel, 1974).

Observations on embryos examined on Day 12 after conception revealed that over $50 \%$ of the affected fetuses had neural tube defects involving the cephalic region, ranging from a collapsed appearance of the hind brain to exencephaly involving the mid- and hind-brain regions.

Véghelyi \& Osztovics (1978) have demonstrated that an acetaldehyde level above $40 \mu \mathrm{M}$ inhibited multiplication of lymphocytes and fibroblasts in culture, and significantly elevated the incidence of sister chromatid exchanges.

Similar neural tube anomalies to those induced by embryonic exposure to acetaldehyde and copper are also observed in certain mutant strains of mice. Observations were made on the offspring of mutant mice bearing Snell's translocation $(\mathrm{T}(2 ; 4) \mathrm{Sn})$, a high proportion of which develops exencephaly and open neural tube defects along the spinal axis (Snell et al., 1935). This work has mainly been carried out by Dr O'Shea (O'Shea, 1979), the mice being obtained from the M.R.C. Radiobiology Unit at Harwell, by courtesy of Dr M. F. Lyon and Ms M. K. Kirk.

Male carriers heterozygous for the translocation were mated to normal females, and the offspring examined between Days 9 and 12 of pregnancy. Approximately $50 \%$ of the embryos died during the early post-implantation period, or survived but developed a range of neural tube abnormalities. The remaining embryos appeared to be quite normal. Apart from evidence of growth retardation, little morphological evidence of neural tube pathology was apparent when surviving embryos were examined on Day 9. On Day 10 open neural tube defects were observed in about $30 \%$ of the living embryos both in the 'cervical' (80\%) and 'spinal' $(20 \%)$ regions of the cord. By Day 11 approximately $20 \%$ of the surviving embryos had a neural tube defect, and in an additional $15 \%$ the head had a flattened appearance from side to side. By Day 12 the incidence of resorptions had increased from a fairly constant level of $20-25 \%$ to almost $40 \%$, while the incidence of neural tube defects in surviving embryos had decreased to just under $20 \%$. The types of 'spinal' defects encountered ranged from moderate to severe spina bifida-like lesions 
at various levels along the neural axis, while the lesions involving the cephalic part of the neural tube ranged from small mid-brain exencephalic defects to detects in which the entire cephalic neural tube had apparently failed to close.

Scanning electron micrographic observations on abnormal embryos showed that even in apparently closed regions the neural tube appeared to be wavy or kinked. In addition, on Day 10 , the surface-neuroepithelial junctional zone was always poorly demarcated. The ruffles, blebs and lamellopodia observed in this region in control material were invariably absent in affected embryos. By Days 11 and 12 the neuroepithelial surface was often rough and characterized by the presence of small blebs and protrusions. In the juxtaluminal region there were two types of neuroepithelial abnormalities; (a) very variable degrees of apical constriction of the cells bordering the lumen, possibly due to irregular spacing of junctional complexes in this region, and (b) the presence of junctional complexes well below their usual location, often some considerable distance from the cell apex. Presumably when constriction of microfilaments occurs this would result in the extrusion of large amounts of cellular material into the lumen.

Because of the considerable variability observed between the morphologically abnormal embryos and fetuses, it appears likely that several closely related faults may be present. At this stage, it is only possible to speculate, but it seems likely that a relationship may exist between the type of unbalanced genotype present and the phenotype of these individuals, the former being related to the location of the duplicated segment and the particular chromosome segment deficiency involved. It would, of course, be necessary to carry out a comprehensive karyotypic analysis on these early embryos to determine whether such a relationship exists. Similar neural tube defects have also been observed in mutant mice bearing the lethal allele $t^{9}$ (T-locus) (Spiegelman \& Bennett, 1974). In these abnormal embryos poorly formed junctional complexes were observed between the underlying mesodermal cells, and it was speculated that this may have played a part in the development of these defects. In the loop tail mutant a similar abnormal neuroepithelial appearance was observed, possibly due to a deficiency of the microfilamentous elements (Wilson, 1978).

Failure of closure of the neural tube, particularly in the cephalic region, is such a sensitive indicator of embryonic exposure to a teratogenic insult in the mouse that the presence of exencephaly at mid-term may at best only serve as a general guide to the timing of exposure to a noxious agent. For embryos with an abnormal karyotype, due to a numerical chromosome anomaly or a mutant gene, the presence of this anomaly may only serve to indicate at which stage during development genome unbalance first begins to be manifest. However, if a reliable incidence of this anomaly is achieved following exposure to a particular agent, observations carried out during the early somite period (just before and shortly after the mouse embryo 'turns' to adopt the characteristic fetal position) on the ultrastructural damage induced within the neuroepithelium and closely related cells may well provide useful clues as to the underlying mode of action of the agent under investigation.

\section{Congenital cardiac disease}

The incidence of congenital cardiac abnormalities in man has been estimated as being of the order of $0.5-0.8 \%$ of all live births (Carter, 1976; Leck, 1977). A very broad spectrum of congenital cardiac defects is recognized, from the presence of relatively mild lesions which may only be manifest during childhood or even later, by minimally reducing the exercise tolerance of the individual, to severe abnormalities which are incompatible with viability beyond a matter of hours after birth.

In one typical series with well-established diagnoses, Campbell (1961) considered 136 patients with 153 cardiac malformations. He observed that the commonest abnormality present was patent ductus arteriosus (58\% of cases), then ventricular septal defect $(18 \%)$, followed by 
atrial septal defect (7\%), tetralogy of Fallot (7\%) and pulmonary valvular stenosis. The incidence of the various types of abnormalities varies quite considerably between individual series. Thus atrial septal defect, for example, generally accounts for about $17 \%$ of the total population with congenital heart disease (Wood, Magidson \& Wilson, 1954), whereas in children's series it is less conspicuous, being fourth in frequency and making up about $7 \%$ of the total. Indeed, this condition may not be diagnosed in up to $50 \%$ of the cases before the age of 18 years. The generally more severe ventricular septal defects account for between 12\% (Nadas, 1957; Lamy, DeGrouchy \& Schweisguth, 1957) and 22\% (Keith, Rowe \& Vlad, 1966) of the cases seen in children's clinics and hospitals dealing with cardiac patients.

In the majority of individuals with congenital cardiovascular defects no obvious etiological factors can be implicated. In only a relatively small proportion is an adequate genetic pedigree or history of exposure to a teratogenic agent available.

A considerable body of evidence is available to suggest that in some cases a genetic mechanism may be involved in the development of congenital heart disease. Some lesions, e.g. supravalvular aortic stenosis, have resulted from the presence of a dominant gene (Jörgensen \& Beuren, 1965), while in some cases of atrial septal defect a typical history of familial inheritance has been observed (Weil \& Allenstein, 1961; for review, see Nora, McNamara \& Clarke Fraser, 1967). However, even when a familial history is available, it is not always possible to exclude persistent environmental or maternal factors which could be responsible. It is now well established that an association often exists between congenital heart disease and chromosome anomalies. This association has frequently been observed in certain trisomic syndromes, such as trisomy 21,18 and 13-15. A fairly high incidence is also observed in Turner's syndrome, but in only a few cases have the cardiovascular anomalies been reliably determined at necropsy. For trisomy 18 and 13-15, with which death commonly occurs within a few months after birth, sufficient necropsies have been carried out to demonstrate both the high incidence of congenital heart disease and the great variability of the pathological findings (Warkany, Passarge \& Smith, 1966).

Many observations are available to suggest that non-genetic post-conception or environmental factors can also induce congenital heart disease (see Warkany, 1971). Numerous studies have shown that many adverse situations during pregnancy can result in congenital heart disease in experimental animals, notably Vitamin A deficiency (Wilson \& Warkany, 1949), hypervitaminosis A (Kalter \& Warkany, 1961), folic acid deficiency (Baird, Nelson, Monie \& Evans, 1954), hypoxia (Ingalls, Curley \& Prindle, 1952), the administration of Trypan blue (Gillman, Gilbert, Gillman \& Spence, 1948) and X-irradiation (Wilson, Jordan \& Brent, 1953). In man, maternal rubella, thalidomide damage, and discordant monozygotic twins also point to the influence of non-genetic factors in many cases of congenital heart disease (for discussion, see Warkany, 1971).

\section{Embryological development of the heart}

The early stages in the development of the mammalian heart are of considerable interest to the embryologist principally because the transport of oxygenated blood and nutrients from the primitive placenta to the tissues of the embryo is first established during the early somite period, and becomes essential when the mass of the conceptus can no longer be adequately nourished by perfusion alone. Once regular contractions take place, the heart must function continuously throughout the life of the individual. At the ultrastructural level, the events associated with the onset of the first irregular contractions, and later by the development of rhythmicity, are paralleled by myocardial cellular differentiation. The first differentiative events to be observed are associated with the process of fibrillogenesis and sarcomere formation, and slightly later by the production of a functional syncytium through the formation of intercalated disks (Challice \& Virágh, 1973; Virágh \& Challice, 1973). 
An examination of the literature has shown that very little information is available on the earliest stages of development of the normal mammalian heart covering the period from the formation of the pericardial-coelomic cavity, and initial laying down of the cardiogenic plate, up to the earliest stages of heart tube formation. However, once loop formation has been initiated, the overall events which take place leading to the formation of the ventricles and atria are reasonably well documented (see, for example, Patten, 1960; Hamilton \& Mossman, 1972), although the embryological terminology used is far from universal, and remains a constant source of confusion (see, for example, discussion in Anderson, Wilkinson \& Becker, 1978).

One of the principal ways of investigating the pathogenesis of certain anomalies of human cardiac development involves the reliable production of phenocopies, either by the administration of teratogenic agents at appropriate stages of gestation, or by the examination of the embryonic stages of mutant strains of animals which commonly develop cardiac anomalies (for example, see Layton, 1978; Patterson, 1978; Buchanan, 1978; Van Mierop \& Patterson, 1978). Sequential observations may then be made to examine the development of the defect in much the same way as described earlier for the examination of anomalies of neural tube development.

To clarify the exact timing and events associated with the transition from the intra-embryonic coelomic to the pericardial cavity, and the formation of the primitive heart tube in mammals, serial standard histological sections through a representative collection of mouse embryos were examined in detail (Kaufman \& Navaratnam, 1981) and an overall descriptive account of the earliest stages of cardiac organogenesis has been prepared. An additional series of embryos was mounted in epoxy resin and semi-thin sections cut at a nominal thickness of $0 \cdot 5-1$ $\mu \mathrm{m}$. 'Thin' sections from appropriate regions of the heart were also taken for subsequent analysis by transmission electron microscopy. In a further group of embryos the body wall overlying the cardiac region was dissected away to expose the contents of the pericardial cavity. This contained the cardiogenic 'plate' in the earliest embryos, and the primitive cardiac loop in more advanced embryos. The pericardial contents were subsequently examined by scanning electron microscopy (Pl. 3, Figs 14-21).

It was evident from the initial histological analysis that the presumptive myocardial rudiments were established by differentiation of the mesothelial-like cells lining the pericardial cavity which were adjacent to the endoderm and in close proximity to the foregut pocket (Kaufman \& Navaratnam, 1981). At first, the cardiogenic 'plate' consists mainly of cuboidal cells which lie on the ventral aspect of the pericardial cavity (Pl. 3, Fig. 15), but later, as a result of the changes which take place in the overall configuration of the embryo, they come to lie on its dorsal wall.

A separate layer of cells forms deep to the primitive myocardium, possibly by differentiation of the underlying mesenchyme. This represents the first evidence of endocardial tissue. By about the time that the first $1-2$ pairs of somites have appeared, cavitation occurs within the endocardial tissue, and establishes a bilaterally symmetrical pair of relatively flattened endocardial tubes (Pl. 3, Fig. 16). Slightly later the myocardial 'plate' which overlies the endocardial tubes appears to bulge into the pericardial cavity. In embryos with about 4 pairs of somites, the endocardial tubes coalesce across the midline to establish a single median cardiac tube which is now suspended in the midline by a wide dorsal mesocardium (Pl. 3, Fig. 17).

These observations seem to be at variance with the widely prevalent view that the endocardial elements in mammalian embryos differentiate from the myocardial (commonly, though possibly incorrectly termed 'myoepicardial' (Manasek, 1969)) cells, and indicate that the endocardial elements are probably formed in situ from the subjacent mesenchyme cells rather than from the myocardial cells as originally proposed by $\mathrm{His}$ (1885), an opinion supported by others (see, for example, Mollier, 1906; Yoshinaga, 1921; Davis, 1927). However, the present observations do not rule out the possibility that both the myocardial and endocardial elements migrate independently into the cardiac region in the manner described for the chick embryo by Rosenquist \& De Haan (1966).

Once the primitive cardiac tube has been formed, and the heart developed an obvious 
venous inflow and arterial outflow tract, termed the sinus venosus and bulbus cordis, respectively, a slight degree of asymmetry now becomes apparent (Pl. 3, Figs 18 and 19). From this stage onwards, the morphology of the embryonic mouse heart closely resembles the general text-book descriptions available of early human heart development (see, for example, Patten, 1960; Sissman, 1970; Hamilton \& Mossman, 1972; for time-table of human cardiogenesis, see O'Rahilly, 1971).

This descriptive account of early heart development has been complemented by ultrastructural studies (M. H. Kaufman, unpublished) which have clearly demonstrated that the increasing degree of cytodifferentiation which takes place over this period is closely paralleled by the functional activity of the primitive heart tube (see also studies by Challice \& Virágh, 1973; Virágh \& Challice, 1973).

The first differentiative event to be observed at the ultrastructural level is probably the laying down within the cytoplasm of discrete contractile elements (Pl. 4, Fig. 22), and their ultimate organization into characteristic cardiac muscle fibres (Pl. 4, Fig. 23) (myofibrillogenesis). The second important developmental step is the formation of a functional syncytium by the anatomical and physiological linking of individual cardiac cells by intercalated disks (P1. 4, Figs 24 and 25). The latter process allows the whole heart to act as an integrated unit. The first contractile elements that are laid down within the cytoplasm of the myocardium have been observed in embryos with 1 or 2 pairs of somites. By the time 4-6 pairs of somites are present the various elements have become aligned to form discrete myofibrillar bundles. Even at this early stage evidence of sarcomere formation is already apparent due to the presence of Z-bands (Pl. 4, Fig. 23), although obvious A and I bands are not yet clearly visible (M. H. Kaufman, unpublished). In embryos with about 6 pairs of somites, evidence of primitive disk formation is also seen (Pl. 4, Fig. 24), and the ultrastructural differentiation which is observed within the cardiac cells is clearly linked to the functional requirements of the heart, as the first regular contractions have been observed at about this time (Goss, 1938). This occurs well before the heart receives any form of innervation (Navaratnam, 1965).

The changes which take place between the simple cardiac-loop stage of development and formation of the 4-chambered heart of the fetus necessitates the establishment and continued functioning of complex associations between cardiac muscle cells and the subjacent endo- and epicardial tissues. The cellular interactions which are thought to be involved during these stages of cardiac morphogenesis have been reviewed by Manasek (1976).

It has also been proposed, on the strength of experimental findings, that some, possibly even a considerable proportion, of the changes involved in cardiac morphogenesis are brought about in response to alterations in cardiovascular haemodynamics (see recent review by Jaffee, 1977). Examples of morphological changes which are almost certainly brought about in this way are the development of the spiral septum in the arterial outflow region of embryonic heart, and, much later, the considerable circulatory changes which take place within the heart and in the circulation at birth. Indeed, temporary, reversible changes in the haemodynamic equilibrium which have been induced by hypoxia have been shown to result in the production of malformations of the heart in the chick embryo (Jaffee, 1974).

\section{Influence of teratogens on cardiac development}

The large number of individual steps which must take place if cardiac organogenesis is to proceed normally, almost certainly involving multiple sequential inductive interactions, presumably explains why the heart and cardiovasular system are so susceptible to teratogenic insult over such a long period of time. However, no clear correlation usually exists between the timing of the teratogenic insult and the type of cardiac abnormality induced, although it seems likely that severe damage incurred at the late primitive-streak stage or during the early somite period, involving interference with myofibrillogenesis or disk formation may, as a result of 
subsequent circulatory failure, be incompatible with viability beyond the early fetal period. However, although this would appear to be a plausible explanation to account for a proportion of early fetal losses, no experimental evidence is available to substantiate this hypothesis. Less severe damage incurred during the early embryonic period is likely to affect looping, and subsequently result in the production of major cardiac abnormalities.

In experimental studies in which early rat embryos were treated with Trypan blue (Monie, Takacs \& Warkany, 1966) or by ionizing irradiation (Fox \& Goss, 1957) transposition of the great vessels was occasionally produced. In all cases, this condition was associated with abnormalities in looping of the primitive heart tube. This experimental evidence would seem to suggest that transposition of the great vessels probably results from damage induced at the time of cardiac looping, and not considerably later by interference with normal morphogenesis of the outflow tract as has previously been thought (for discussion, see Pexieder, 1978). This would also seem to be a relatively clear instance in which interference with looping produced sequelae involving the derivatives of the branchial arch vasculature, rather than the structural components of the heart itself, although the developmental processes of the two are, of course, intimately related. The validity of looping as a general model of cardiac morphogenesis has been discussed by Manasek, Kulikowski \& Fitzpatrick (1978), and the observation made that several differences exist between hearts at the time of looping and hearts at later stages of morphogenesis, particularly in their response to alterations in blood flow; initially, looping proceeds in the absence of blood flow, but later morphogenetic processes may be altered if blood flow is disturbed. However, the analysis of the looping process does provide insight into the factors which influence the shape of developing cardiac muscle cells (Manasek, Burnside \& Waterman, 1972). This is of fundamental importance, since these changes in cell shape are responsible for establishing the basic shape of the developing heart.

The morphological and structural changes which are associated with looping are closely correlated with cytodifferentiation of the cardiac muscle cells, as the transition from the 'undifferentiated' myoblast cell to the developing myocyte takes place at this time. That these events are causally related seems clear from the experimental finding that prevention of myofibrillar assembly by various agents, such as inhibitors of protein synthesis and substances which act on 'cytoskeletal' or 'contractile' proteins (for details, see Manasek, 1976), prevent looping. Okamoto (1968) reported a maximal incidence of cardiovascular anomalies ( $84.6 \%)$ in rat embryos, when pregnant females were exposed on the 8th day after conception to a single dose of 130 rads of whole-body neutron irradiation. Transposition of the great vessels was found in $69.2 \%$ of these abnormal embryos. In a particularly thorough survey on the effect of neutron irradiation on rat embryos, Satow, Okamoto, Hidaka, Akimoto \& Miyabara (1978) studied the ultrastructural changes occurring within cardiac myocytes in the 24 -h period after irradiation. Maximal effects were observed at about $6 \mathrm{~h}$ after treatment (see also Satow, 1971; Ikeda, Okamoto \& Satow, 1972), with pycnosis, dilated rough endoplasmic reticulum and/or mitochondria, and vacuolation. In the embryos which survived up to the end of the 2 nd day after irradiation, no evidence of cellular degeneration was observed in the heart, although a slight retardation of embryonic growth and development was noticed in most cases, as were anomalies of looping. However, a range of morphological anomalies was observed when fetuses were examined up to 11 days after irradiation, and it was proposed that these abnormalities probably resulted from 'disorders of the various germ layer derivatives, effects of irradiation on genes, and to a decrease in the number of cardiac cells present as a result of cell death following irradiation treatment'.

After looping has been achieved, and the overall shape of the myocardial cells has been relatively stabilized due to the increasing degree of cytodifferentiation which takes place within and between them, it is likely that abnormalities involving later states of cardiac development result from interference with other morphogenetic mechanisms acting at these times. For example, it is well recognized that 'physiological' or 'programmed' cell death plays an important 
part in the later stages of the development of the heart and circulation (chick: Hughes, 1948; Manasek, 1969; Menkes, Dandor \& Illies, 1970; Pexieder, 1975; rat: Okamoto \& Satow, 1975). Differential tissue growth also plays an important role during the later post-looping stages of cardiogenesis, and this aspect of cardiac growth is closely related to the complex interactions which take place between dissimilar cell types at this time (for extensive discussion on the morphogenetic significance of tissue interactions during cardiac development in the chick embryo, see Manasek, 1976).

It will be apparent from the previous discussion that additional basic descriptive and experimental embryological and teratological work will have to be carried out before a thorough understanding of the morphogenetic factors which influence normal mammalian cardiogenesis can be achieved. Only then will it be possible to understand the sequential changes that occur during the production of anomalies of the heart and cardiovascular system. As with the study of neural tube abnormalities, it is essential that comprehensive accounts of the normal events associated with cardiogenesis should be available to the teratologist. These studies should not only present a picture of the normal sequence of events occurring during cardiac development, but should also indicate the degree of variability which may be encountered between individual embryos, between strains and between different species.

Because of the very limited amount of human embryonic material available covering the earliest stages of organogenesis, it seems likely that, in the forseeable future, mammalian embryologists will have to be satisfied with the analysis of rodent and possibly non-human primate material. Certainly, during the more advanced stages and possibly even during the earlier stages of cardiogenesis, this mammalian material more closely resembles early human development than the almost universally employed chick model which in many respects bears a stronger resemblance to the reptilian heart. It should also be recalled that some of the early somite-stage human embryos, e.g. after therapeutic termination of pregnancy, might in any case have been aborted spontaneously shortly thereafter, possibly as a result of anomalies of the cardiovascular system. In addition, the very low incidence of spontaneous embryonic and fetal losses in rodents, and the presence of very few gross morphological abnormalities in surviving offspring, would appear to be an additional factor in favour of continuing to concentrate our efforts in the analysis of morphogenetic events in these experimental animals.

\section{Conclusions}

By understanding in morphological terms how a range of environmental teratogens act under controlled conditions in experimental animals, and appreciating how certain genetically determined lesions are produced, it may then be possible to draw certain conclusions which may go some way towards assisting our understanding of the pathogenesis of similar lesions which occur in man (Poswillo, 1976; Clarke Fraser, 1977). It is also likely to be by this means that a rational approach to the treatment of certain human congenital abnormalities may be achieved. In other instances, knowledge of their pathogenesis may indicate how certain conditions may be prevented, or their incidence considerably reduced. Because this goal is unlikely to be achieved in the near future, it is, of course, essential to improve the efficiency of early prenatal diagnostic methods capable of recognizing major congenital anomalies (see, for example, Brock, 1976; Laurence \& Gregory, 1976; MacVicar, 1976).

While extrapolation from the results of animal experiments to man must only be carried out with extreme caution, I believe that the principal long-term aim of experimental teratology must be towards achieving a reduction in the present high incidence of human congenital abnormalities by prophylactic measures, if at all possible. The ultimate aim must therefore be towards the encouragement of rational forms of treatment in these cases, based on a foundation of sound experimental studies. 
The work is supported by a grant from the National Fund for Research into Crippling Diseases.

\section{References}

Akabane, J. (1970) Aldehydes and related compounds. Int. Encyclopedia Pharm. Therap. 2, 523-560.

Anderson, R.H., Wilkinson, J.L. \& Becker, A.E. (1978) The bulbus cordis - a misunderstood region of the developing human heart: its significance to the classification of congenital cardiac malformations. Birth Defects 14, 1-28.

Baird, C.D., Nelson, M.M., Monie, I.W. \& Evans, H.M. (1954) Congenital cardiovascular anomalies induced by pteroylglutamic acid deficiency during gestation in the rat. Circulation Res. 2, 544-554.

Boué, J. \& Boué, A. (1973) Anomalies chromosomiques dans les avortements spontanés. In Les Accidents Chromosomiques de la Reproduction, pp. 29-55. Eds A. Boué \& C. Thibault. Institut National de la Santé et de la Rechere Médicale, Paris.

Brinster, R.L. \& Cross, P.C. (1972) Effect of copper on the preimplantation mouse embryo. Nature, Lond. 238, 398-399.

Brock, D.J.H. (1976) Prenatal diagnosis-Chemical methods. Br. med. Bull. 32, 16-20.

Buchanan, J.W. (1978) Morphology of the ductus arteriosus in fetal and neonatal dogs genetically predisposed to patent ductus arteriosus. Birth Defects 14, 349-360.

Campbell, M. (1961) Place of maternal rubella in the aetiology of congenital heart disease. Br. med. J. 1, 691-705.

Carter, C.O. (1974) Clues to the aetiology of neural tube malformations. Dev. Med. Child Neurol. Suppl. 32, $3-15$.

Carter, C.o. (1976) Genetics of common single malformations. Br. med. Bull. 32, 21-26.

Challice, C.E. \& Virágh, S. (1973) The embryonic development of the mammalian heart. In Ultrastructure of the Mammalian Heart, pp. 91-126. Eds C. E. Challice \& S. Virágh. Academic Press, New York.

Chernoff, G.F. (1977) The fetal alcohol syndrome in mice: an animal model. Teratology 15, 223-229.

Clarke Fraser, F. (1977) Relation of animal studies to the problem in man. In Handbook of Teratology, Vol. 1, pp. 75-96. Eds J. G. Wilson \& F. Clarke Fraser. Plenum Press, New York.

Davis, C.L. (1927) Development of the human heart from its first appearance to the stage found in embryos of twenty paired somites. Contr. Embryol. Carneg. Inst. 19, 245-284.

Ferm, V.H. \& Hanlon, D.P. (1974) Toxicity of copper salts in hamster embryonic development. Biol. Reprod. 11, 97-101.

Ford, C.E. (1975) The time in development at which gross genome unbalance is expressed. In The Early Development of Mammals, pp. 285-304. Eds M. Balls \& A. E. Wild. Cambridge University Press.

Fox, M.H. \& Goss, C.M. (1957) Experimentally produced malformations of the heart and great vessels in rat fetuses. Atrial and caval abnormalities. Anat. Rec. 129, 309-322.

Gillman, J., Gilbert, C., Gillman, T. \& Spence, I. (1948) A preliminary report of hydrocephalus, spina bifida, and other congenital anomalies in the rat produced by trypan blue. S. Afr. J. med. Sci. 13, 47-90.

Gosden, C., Ross, A., McGovern, A. \& Reid, W. (1979) The state of the device and copper levels in the products of conception in women becoming pregnant with a copper-bearing IUD in situ. J. Reprod. Fert. $55,437-446$.

Goss, C.M. (1938) The first contractions of the heart in rat embryos. Anat. Rec. 70, 505-524.

Hamerton, J.L. (1971) Human Cytogenetics: Vol. 2, Clinical Cytogenetics. Academic Press, New York.

Hamilton, W.J. \& Mossman, H.W. (1972) Human Embryology: Prenatal Development of Form and Function, 4th edn. W. Heffer \& Sons, Cambridge.

Henderson, G.I. \& Schenker, S. (1977) The effect of maternal alcohol consumption on the viability and visceral development of the newborn rat. Res. Comm. Chem. Path. Pharm. 16, 15-32.

His, W. (1885) Anatomie menschlicher Embryonen, Vol. 3. Leipzig.

Hsu, L.Y.F. \& Hirschhorn, K. (1977) Numerical and structural chromosome abnormalities. In Handbook of Teratology, Vol. 2, pp. 41-80. Eds J. G. Wilson \& F. Clarke Fraser. Plenum Press, New York.

Hughes, A.F.W. (1948) The histogenesis of arteries in the chick embryo. J. Anat. 77, 266-287.

Hughes, A.F.W. (1976) Developmental biology and the study of malformations. Biol. Rev. 51, 143-179.

Ikeda, T., Okamoto, N. \& Satow, Y. (1972) Effects of fast neutron irradiation on $\mathrm{LDH}$ - and $\mathrm{MDH}$-isozyme in developing rat embryos with special regard to abnormal cardiogenesis. Hiroshima J. med. Sci. 21, 79-89.

Ingalls, T.H., Curley, F.J. \& Prindle, R.A. (1952) Medical progress: experimental production of congenital anomalies; timing and degree of anoxia as factors causing fetal deaths and congenital anomalies in mice. New Engl. J. Med. 247, 758-768.

Jaffee, O.C. (1974) The effects of moderate hypoxia and moderate hypoxia with hypercapnea on cardiac development in chick embryos. Teratology 10, 275-281.

Jaffee, O.C. (1977) Abnormal organogenesis in the cardiovascular system. In Handbook of Teratology, Vol. 2, pp. 343-364. Eds J. G. Wilson \& F. Clarke Fraser. Plenum Press, New York.

Jones, K.L., Smith, D.W., Ulleland, C.N. \& Streissguth, A.P. (1973) Pattern of malformation in offspring of chronic alcoholic mothers. Lancet i, 1267-1271.

Jörgensen, G. \& Beuren, A.J. (1965) Genetische untersuchungen bei supravalvulären dortenstenosen. Humangenetik 1, 497-515.

Kalter, H. (1968) Teratology of the Central Nervous System. University of Chicago Press, Chicago. 
Kalter, H. \& Warkany, J. (1961) Experimental produc tion of congenital malformations in strains of inbred mice by maternal treatment with hypervitaminosis $\mathrm{A}$. Am. J. Path. 38, 1-21.

Karfunkel, P. (1974) The mechanisms of neural tube formation. Int. Rev. Cytol. 38, 245-271.

Kaufman, M.H. (1979) Cephalic neurulation and optic vesicle formation in the early mouse embryo. Am. J. Anat. 155, 425-444.

Kaufman, M.H. \& Navaratnam, V. (1981) Early differentiation of the heart in mouse embryos. J. Anat. (in press).

Keith, J.D., Rowe, R.D. \& Vlad, P. (Eds) (1966) Heart Disease in Infancy and Childhood, 2nd edn. Macmillan, New York.

Kochhar, D.M. \& Larsson, K.S. (1977) Alterations in the metabolism of glycosaminoglycans and collagen. In Handbook of Teratology, Vol. 2, pp. 231-269. Eds J. G. Wilson \& F. Clarke Fraser. Plenum Press, New York.

Kronick, J.B. (1976) Teratogenic effects of ethyl alcohol administered to pregnant mice. Am. J. Obstet. Gynec. 124, 676-680.

Lamy, M., DeGrouchy, J. \& Schweisguth, O. (1957) Genetic and non-genetic factors in the etiology of congenital heart disease: A study of 1188 cases. Am. J. Human Genet. 9, 17-41.

Laurence, K.M. \& Gregory, P. (1976) Prenatal diagnosis of chromosome disorders. Br. med. Bull. 32, 9-15.

Layton, W.M., Jr (1978) Heart malformations in mice homozygous for a gene causing situs inversus. Birth Defects 14, 277-294.

Leck, I. (1972) The etiology of human malformations: insights from epidemiology. Teratology 5, 303-314.

Leck, I. (1974) Causation of neural tube defects: clues from epidemiology. Br. med. Bull. 30, 158-163.

Leck, I. (1977) Correlations of malformation frequency with environmental and genetic attributes in man. In Handbook of Teratology, Vol. 3, pp. 243-324. Eds J. G. Wilson \& F. Clarke Fraser. Plenum Press, New York.

MacVicar, J. (1976) Antenatal detection of fetal abnormality-physical methods. Br. med. Bull. 32, 4-8.

Manasek, F.J. (1969) Embryonic development of the heart. II. Formation of the epicardium. J. Embryol. exp. Morph. 22, 333-348.

Manasek, F.J. (1970) Sulfated extracellular matrix production in the embryonic heart and adjacent tissues. J. exp. Zool. 174, 415-423.

Manasek, F.J. (1976) Heart development: interactions involved in cardiac morphogenesis. In The Cell Surface in Animal Embryogenesis and Development, Vol. 1, pp. 545-598. Eds G. Poste \& G. L. Nicolson. North Holland Publishing Company, Amsterdam.

Manasek, F.J., Burnside, B. \& Waterman, R.E. (1972) Myocardial cell shape change as a mechanism of embryonic heart looping. Devl Biol. 29, 349-371.

Manasek, F.J., Kulikowski, R.R. \& Fitzpatrick, L. (1978) Cytodifferentiation: a causal antecedent of looping? Birth Defects 14, 161-178.

Menkes, B., Dandor, S. \& Illies, A. (1970) Cell death in teratogenesis. Adv. Teratol. 4, 170-215.

Miller, J.R. \& Lowry, R.B. (1977) Birth defects registries and surveillance. In Handbook of Teratology, Vol. 3, pp. 227-242. Eds J. G. Wilson \& F. Clarke Fraser. Plenum Press, New York.

Mollier, S. (1906) Die erste anlage des herzens bei den wirbeltieren. Hertwig Handb. vergl. exp. Entwickl. Wirbelt. 1, 1021-1051.

Monie, I.W., Takacs, E. \& Warkany, J. (1966) Transposition of the great vessels and other cardiovascular abnormalities in rat fetuses induced by trypan blue. Anat. Rec. 156, 175-190.

Morriss, G.M. \& Solursh, M. (1978) Regional differences in mesenchymal cell morphology and glycosaminoglycans in early neural fold stage rat embryos. $J$. Embryol. exp. Morph. 46, 37-52.

Mulvihill, J.J. \& Yeager, A.M. (1976) The fetal alcohol syndrome. Teratology 13, 345-348.

Nadas, A.S. (1957) Pediatric Cardiology. W. B. Saunders Company.

Naeslund, G. (1972) Blastocystotoxic effects of copper in vitro. Contraception 6, 281-285.

Navaratnam, V. (1965) Development of the nerve supply to the human heart. Br. Heart J. 27, 640-650.

New, D.A.T., Coppola, P.T. \& Terry, S. (1973) Culture of explanted rat embryos in rotating tubes. J. Reprod. Fert. 35, 135-138.

Nora, J.J., McNamara, D.G. \& Clarke Fraser, F. (1967) Hereditary factors in atrial septal defect. Circulation $35,448-456$.

Okamoto, N. (1968) Morphology and classification of cardiovascular anomalies induced by $14.1 \mathrm{MeV}$ neutron irradiation. Proc. Hiroshima Univ. RINMB $9,25-42$.

Okamoto, N. \& Satow, Y. (1975) Cell death in bulbar cushion of normal and abnormal developing heart. In Development and Physiological Correlates of Cardiac Muscle, pp. 51-65. Eds M. Lieberman \& T. Sano. Raven Press, New York.

O'Rahilly, R. (1966) The timing and sequence of events in staged human embryos. Contr. Embryol. Carneg. Inst. 38, 1-42.

O'Rahilly, R. (1971) The timing and sequence of events in human cardiogenesis. Acta anat. 79, 70-75.

O'Shea, K.S.O. (1979) The neuroepithelium in mouse neural tube closure. Ph.D. thesis, University of Cambridge.

O'Shea, K.S. \& Kaufman, M.H. (1979a) The teratogenic effect of acetaldehyde: implications for the study of the fetal alcohol syndrome. J. Anat. 128, 65-76.

O'Shea, K.S. \& Kaufman, M.H. (1979b) Influence of copper on the early post-implantation mouse embryo: an in vivo and in vitro study. Wilh. Roux Arch. EntwMech. Org. 186, 297-308.

O'Shea, K.S. \& Kaufman, M.H. (1980) Copper-induced microtubule degeneration and filamentous inclusions in the neuroepithelium of the mouse embryo. Acta neuropath. 49, 237-240.

O'Shea, K.S. \& Kaufman, M.H. (1981) Effect of acetaldehyde on the neuroepithelium of early mouse embryos. J. Anat. 132, 107-1 18.

Papara-Nicholson, D. \& Telford, I.R. (1957) Effects of alcohol on reproduction and fetal development in the guinea pig. Anat. Rec. 127, 438-439.

Patten, B.M. (1960) The development of the heart. In Pathology of the Heart, 2nd edn, pp. 24-92. Ed. S. E. Gould. Charles C. Thomas, Springfield. 
Patterson, D.F. (1978) Lesion-specific genetic factors in canine congenital heart disease: patent ductus arteriosus in poodles, defects of the conotruncal septum in the keeshond. Birth Defects 14, 315-348.

Pexieder, T. (1975) SEM investigations on physiological cell death in the chick embryo heart. Experientia 31, 745 .

Pexieder, T. (1978) Development of the outflow tract of the embryonic heart. Birth Defects 14, 29-68.

Poswillo, D. (1976) Mechanisms and pathogenesis of malformation. Br. med. Bull. 32, 59-64.

Rahwan, R.G. (1974) Speculations on the biochemical pharmacology of ethanol. Life Sciences 15, 617633.

Randall, C.L., Taylor, W.J. \& Walker, D.W. (1977) Ethanol-induced malformations in mice. Alcoholism 1, 219-24.

Rosenquist, G.C. \& De Haan, R.L. (1966) Migration of precardiac cells in the chick embryo: a radioautographic study. Contr. Embryol. Carneg. Inst. 38, $113-121$.

Rosman, N.P. \& Malone, M.J. (1976) An experimental study of the fetal alcohol syndrome. Neurology 26, 365.

Rychter, Z. (1962) Experimental morphology of the aortic arches and heart loop in chick embryos. $A d v$. Morph. 2, 333-371.

Sandor, S. \& Amels, D. (1971) The action of aethanol on the praenatal development of albino rats. Revue roum. Embryol. Cytol. Ser. Embryol. 8, 105-118.

Satow, Y. (1971) Electron microscopic study on the embryonic heart induced by fast neutron irradiation. Hiroshima J. med. Sci. 19, 21-40.

Satow, Y., Okamoto, N., Hidaka, N., Akimoto, N. \& Miyabara, S. (1978) Intracellular mechanism of teratogenesis of embryonic heart. Birth Defects 14, $251-271$.

Sissman, N.J. (1970) Developmental landmarks in cardiac morphogenesis: Comparative chronology. Am. J. Cardiol. 25, 141-148.

Smithells, R.W., Sheppard, S., Schorach, C.J., Seller, M.J., Nevin, N.C., Harris, R., Read, A.P. \& Fielding, D.W. (1980) Possible prevention of neural-tube defects by periconceptional vitamin supplementation. Lancet i, 339-340.

Snell, G.D., Bodeman, E. \& Hollander, W. (1935) A translocation in the house mouse and its effect on development. J. exp. Zool. 67, 93-104.

Solursh, M. \& Morriss, G.M. (1977) Glycosaminoglycan synthesis in rat embryos during the formation of the primary mesenchyme and neural folds. Devl Biol. 57, 35-86.

Spiegelman, M. \& Bennett, D. (1974) Fine structural study of cell migration in the early mesoderm of normal and mutant mouse embryos. (T-locus: $\mathrm{t}^{\mathrm{a}} / \mathrm{t}^{\mathrm{a}}$ ). J. Embryol. exp. Morph. 32, 723-738.

Staats, J. (1975) Inbred strains of mice, No. 9. The Jackson Laboratory, Bar Harbor, Maine.

Staats, J. (1976) Standardized nomenclature for inbred strains of mice: sixth listing. Cancer Res. 36, 4333-4377.

Steele, C.E. \& New, D.A.T. (1974) Serum variants causing the formation of double hearts and other abnormalities in explanted rat embryos. $J$. Embryol. exp. Morph. 31, 707-719.

Streeter, G.L. (1942) Developmental horizons in human embryos. Description of age group XI, 13-20 somites and age group XII, 21-29 somites. Contr. Embryol. Carneg. Inst. 30, 211-245.

Trasler, D.G. \& Clarke Fraser, F. (1977) Time-position relationships with particular reference to cleft lip and cleft palate. In Handbook of Teratology, Vol. 2, pp. 271-292. Eds J. G. Wilson \& F. Clarke Fraser. Plenum Press, New York.

Truitt, E.B., Jr \& Walsh, M.J. (1971) The role of acetaldehyde in the actions of ethanol. In The Biology of Alcoholism, Vol. 1, Biochemistry, pp. 161-195. Eds, B. Kissin \& H. Begleiter. Plenum Press, New York.

Tze, W.J. \& Lee, M. (1975) Adverse effects of maternal alcohol consumption on pregnancy and foetal growth in rats. Nature, Lond. 257, 479-480.

Van Mierop, L.H.S. \& Patterson, D.F. (1978) The pathogenesis of spontaneously occurring anomalies of the ventricular outflow tract in Keeshond dogs: embryonic studies. Birth Defects 14, 361-376.

Véghelyi, P.V. \& Osztovics, M. (1978) The alcohol syndromes: the intrarecombigenic effect of acet aldehyde. Experientia 34, 195-196.

Virágh, S. \& Challice, C.E. (1973) Origin and differentiation of cardiac muscle cells in the mouse. J. Ultra struct. Res. 42, 1-24.

Warkany, J. (1971) Congenital malformations: notes and comments. Year Book Medical Publishers Inc., Chicago.

Warkany, J., Passarge, E. \& Smith, L.B. (1966) Congenital malformations in autosomal trisomy syndromes. Am. J. Dis. Child. 112, 502-517.

Weatherall, J.A.C. \& Haskey, J.C. (1976) Surveillance of malformations. Br. med. Bull. 32, 39-44.

Webb, F.T.G. \& Coppola, P.T. (1976) Intrauterine copper: effects on post-implantation development. In Recent Developments in Contraceptive Technology, pp. 35-42. Ed. R. R. Lauman. Ankur, New Delhi.

Weil, M.H. \& Allenstein, B.J. (1961) a report of congenital heart disease in five members of one family. New Engl.J. Med. 265, 661-667.

Willis, R.A. (1962) The Borderland of Embryology and Pathology, 2nd edn. Butterworths, London.

Wilson, D.B. (1978) The fine structure of ventricular cells in the brains of mouse embryos homozygous for the loop-tail gene. Teratology 17, 115-136.

Wilson, J.G. \& Warkany, J. (1949) Aortic-arch and cardiac anomalies in the offspring of vitamin A deficient rats. Am. J. Anat. 85, 113-156.

Wilson, J.G., Jordan, H.C. \& Brent, R.L. (1953) Effects of irradiation on embryonic development. II. X-rays on the ninth day of gestation in the rat. Am.J.Anat. 92, $153-188$.

Wood, P., Magidson, O. \& Wilson, P.A.O. (1954) Ventricular septal defect with note on acyanotic Fallot's tetralogy. Br. Heart J. 16, 387-406.

Yoshinaga, S. (1921) A contribution to the early development of the heart in mammalia, with special reference to the guinea pig. Anat. Rec. 21, 239-308. 